\title{
Lessons of the month 1: Journal anxiety
}

\author{
Authors: Ilia Anna Petrou, ${ }^{A}$ Siao Pei $\operatorname{Tan}^{B}$ and Andrew Birnie ${ }^{C}$
}

KEYWORDS: Journals, anxiety, CME

DOI: 10.7861/clinmed.2019-0425

\section{Introduction}

The explosion of medical knowledge in the 21st century may be reflected in the volume of journals arriving through our letterboxes. In this carbon-conscious information age, does receiving a multitude of journals translate into better patient care or stimulate anxiety among clinicians for missing out on the latest medical advances?

\section{Aim}

We aimed to explore clinicians' habits, preferences and concerns around journal reading.

\section{Methods}

A multiple-choice 10-question questionnaire on SurveyMonkey was sent out, via email, to all doctors working in the East Kent Hospitals NHS Foundation Trust and the Medway NHS Foundation Trust (www.surveymonkey.co.uk/r/Z8TF6NS).

\section{Results}

A total of 207 responses were collected. The respondents' demographics are represented in Fig 1.

Ninety-five per cent $(n=196)$ were not in an academic clinical post (defined as dedicating $\geq 25 \%$ of their time to teaching/ research); $47 \%(n=98)$ and $41 \%(n=84)$ of respondents received $1-2$ and $3-5$ journals monthly, respectively.

Only $3 \%(n=6)$ of respondents read their journals 'from-coverto-cover'; $7 \%(n=15)$ read $\geq 50 \%$ of them; $27 \%(n=56)$ read $<25 \%$ of journals; and $29 \%(n=59)$ reported hardly reading their journals at all.

Authors: ${ }^{A}$ F2 WAST doctor, Medway NHS Foundation Trust, Gillingham, UK; ${ }^{\text {B }}$ specialist registrar in dermatology, East Kent Hospitals University NHS Foundation Trust, Canterbury, UK; ${ }^{C}$ consultant in dermatology, East Kent Hospitals University NHS Foundation Trust, Canterbury, UK
Thirty-three per cent $(n=69)$ reported keeping their journals to read when they 'have lots of spare time'; and $82 \%(n=169)$ wished they had more time for journal-reading.
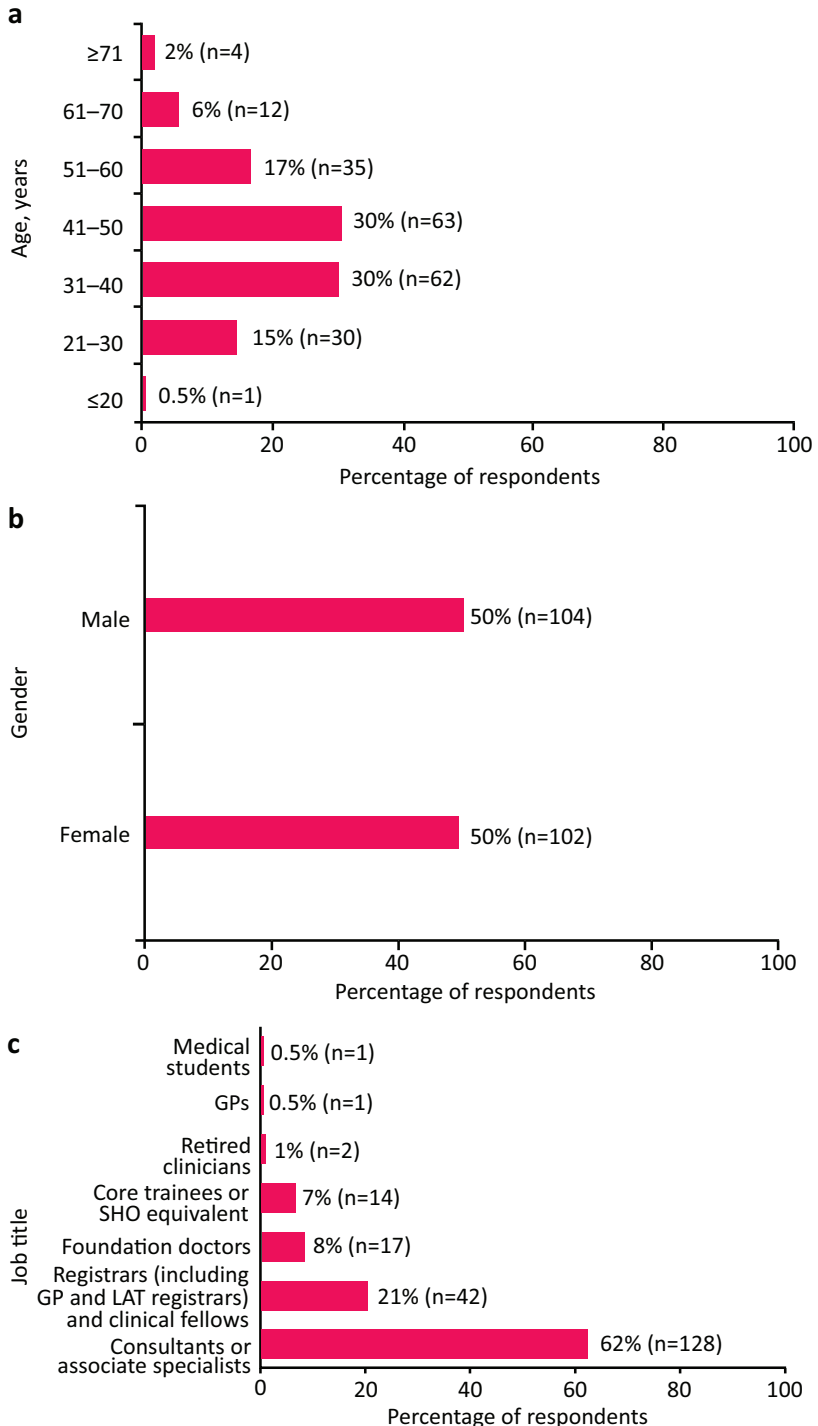

Fig 1. Demographics of survey respondents. a) Age. b) Gender. c) Job title. $\mathrm{GP}=$ general practitioner; $\mathrm{LAT}=$ locum appointment for training; $\mathrm{SHO}=$ senior house officer. 
Forty-three per cent $(n=90)$ read only publications that interest or relate to them while $37 \%(n=76)$ just read the abstract or conclusion.

Fifty-seven per cent $(n=118)$ and $23 \%(n=48)$ were 'slightly' and 'very' concerned that they may 'miss out on the latest advances' when not reading their journals, respectively. The remaining 20\% ( $n=41$ ) were not concerned.

While $15 \%(n=30)$ of respondents reported genuinely $100 \%$ enjoying journal reading, $6 \%(n=13)$ did not enjoy it and $17 \%$ $(n=35)$ reported enjoying their journals 'a little'.

Thirty-seven per cent $(n=77)$ of respondents recycle their journals.

Thirty-eight per cent $(n=79)$ of respondents would choose electronic journals, with a discount on the subscription fees. Paperonly copies were preferred by $17 \%(n=35)$.

\section{Discussion}

A significant proportion (29\%) of respondents admitted to hardly reading journals, with four-fifths of them being concerned about keeping up with the latest medical advances when not reading them. Hence, a common pattern of so-called 'journal anxiety' was identified. Most respondents wished they had more time for journal reading.

With a discount on subscription fee, $>1 / 3$ of respondents would choose electronic over paper journals. This reflects both the trend of using digital media for learning purposes and the growing awareness of our carbon footprint. Replacing printed content with digital information services in libraries has been found to reduce greenhouse gas emissions. ' In this digital age, when knowledge is a mouse click away, perhaps it is time to shelve our paper-flicking habit. However, the associations who run the journals may be reluctant to move away from print editions as a significant proportion of their income comes from advertising and reprints of the journal articles. We acknowledge that having a majority of our respondents being consultants, in non-academic posts, may contribute a potential bias.

\section{Conclusion}

We recognised 'journal anxiety' - concern regarding keeping abreast of the latest advances when not reading medical journals - and lack of time for journal reading to be a common feature among most of our respondents.

\section{Recommendations}

We recommend dedicated journal time at the workplace, eg journal clubs, should be encouraged and that receiving hard copies of journals could be made an opt-in, not an opt-out, system.

\section{Reference}

1 Chowdhury G. How digital information services can reduce greenhouse gas emissions. Online Information Review 2012;36:489-506.

Address for correspondence: Dr Ilia Anna Petrou, Friends Dermatology Centre, 1937 Building - Main Floor, Kent and Canterbury Hospital, Ethelbert Road, Canterbury, Kent CT1 3NG, UK.

Email: ilia.petrou@nhs.net 